\title{
The Effect of Tranexamic Acid in Patients with Traumatic Brain Injury Samir M Atia ${ }^{1}$, Mostafa Mahmoud Nabeeh ${ }^{2}$, Mohamed Elsaid Ahmed ${ }^{3}$, Ahmed Essam Mohamed Elsokary ${ }^{4}$ \\ Departments of ${ }^{1}$ Vascular Surgery, ${ }^{2}$ Neurosurgery, ${ }^{3}$ Critical Care Medicine and \\ ${ }^{4}$ Emergency Medicine, Faculty of Medicine, Mansoura University,Egypt. \\ Corresponding author: Ahmed Essam Mohamed Elsokary, Mobile: (+20) +201112256623, \\ E-Mail: dr.melfeqy90@gmail.com
}

\begin{abstract}
Background: Traumatic brain injury (TBI) is a leading cause of death and disability. Intracranial hemorrhage secondary to TBI is associated with a high risk of coagulopathy, which leads to increasing risk of hemorrhage growth, poor functional outcome and higher mortality rate. The hemostatic drug tranexamic acid with anti-fibrinolytic activity is usually used in patients with trauma. Because of its potential role in reducing hematoma size, which prevents secondary TBI, it has been considered a possible therapy to improve the clinical outcome in patients with TBI.

Objective: To evaluate the effect of tranexamic acid on volume changes of intracranial bleeding in patients with TBI admitted to Emergency Department at Mansoura University Emergency Hospital.

Patients and methods: This is prospective interventional study randomized controlled trials carried out on 100 patients with TBI and admitted at Mansoura University Emergency Hospital; a level 1 trauma center with about 250,000 visits and 25000 trauma cases admission per year, through one year from October 2019 to October 2020.

Results: The clinical outcome was better in tranexamic group as it was associated significantly with improved motor GCS and less need for neurosurgical intervention. The secondary outcome was much better in tranexamic acid group which was associated with less hospital LOS, better GOS and less mortality rate.

Conclusion: Early administration of tranexamic acid (within 3 hours of injury onset) can limit the extent of bleeding before the hemorrhagic volume may become dangerous, while late administration can be useless.
\end{abstract}

Keywords: Tranexamic Acid, Traumatic Brain Injury.

\section{INTRODUCTION}

Trauma is the first cause of death before 40 years of age and is responsible for numerous definitive handicaps and high costs. Trauma is a time-sensitive condition. Especially during the first hour of trauma management, assessment, resuscitation and definitive care are very important. Providing definitive care earlier at trauma centers has been shown to decrease mortality (1).

Traumatic brain injury (TBI) is a major cause of death and disability worldwide, especially in children and young adults and presents a major social, economic, and health problem. TBI is defined as damage to brain resulting from external mechanical force, such as rapid acceleration or deceleration, impact, blast waves and penetration by projectile. Brain function is temporarily or permanently impaired with structural damage (2). Head injuries are among the most common types of trauma encountered in emergency departments (EDs). Traumatic brain injury (TBI) is commonly accompanied by intracranial bleeding, which occurs in $25 \%$ to $45 \%, 3 \%$ to $12 \%$ and $0.2 \%$ of severe, moderate and mild TBI cases respectively ${ }^{(3)}$. In patients with TBI, intracranial bleeding can develop or worsen after hospital admission. Study involving repeated CT scanning have found that intracranial bleeds can develop or expand in the 24 hours after injury ${ }^{(4)}$.

Tranexamic acid (TXA) is a potent antifibrinolytic agent that exerts its effect by blocking lysine binding sites on plasminogen molecules and has the potential to enhance the effectiveness of the patient's own hemostatic mechanisms. Consequently, clot breakdown (fibrinolysis) is inhibited and excessive or recurrent bleeding is reduced. TXA may be commonly used in surgery to reduce blood loss ${ }^{(5)}$. TXA also has an excellent safety profile and has been shown to be cost-effective. Because of the mechanistic potential for TXA to decrease secondary brain injury it has been considered as a possible therapy to improve clinically important outcomes in patients with TBI by reducing systemic blood loss. Hypotension is an established risk factor for poor outcome after TBI ${ }^{(6)}$.

The aim of the work was to evaluate the effect of tranexamic acid on volume changes of intracranial bleeding in patients with TBI admitted to Emergency Department at Mansoura University Emergency Hospital.

\section{PATIENTS AND METHODS}

This is prospective interventional study (Randomized Controlled Trials (RCT)) carried out on 100 patients with TBI and admitted at Mansoura University Emergency Hospital; a level 1 trauma center with about 250,000 visits and 25000 trauma cases admission per year, through one year from October 2019 to October 2020. The studied patients were divided into 2 groups: tranexamic group (50 patients) who were given tranexamic acid and control group (50 
patients) who received the standard medical care without tranexamic acid.

\section{Inclusion criteria:}

○ Older than 18 years

○ Both genders

- Isolated TBI

- Traumatic intracranial bleedings in admission CT brain

- Presented within 3 hours of injury onset

$\circ$ No immediate indication for surgery

\section{Exclusion criteria:}

O Patients whose relatives refused to participate in the $\mathbf{V}$. study

○ Pregnant women

$\bigcirc$ Neurosurgical intervention before $2^{\text {nd }} \mathrm{CT}$ scan

O Patients for whom a $2^{\text {nd }}$ brain scan was not possible because of hemodynamic instability or death

- Serum creatinine over than $2 \mathrm{mg} / \mathrm{dl}$

- Known to be receiving a medication which affects hemostasis

- Evidences of coagulopathy: if any of the following hematological parameters were observed:

* Platelet count less than 100,000 cells/mm3

* Prothrombin time (PT) or international normalized ratio $($ INR) $>1.5$ times normal value

* Activated partial thromboplastin time (aPTT) > 10 seconds greater than normal value.

\section{All patients were subjected to:}

\section{The primary survey:}

The initial resuscitation occurs concurrently with primary assessment. The primary assessment was proceed with using the "ABCDE" approach.

A. Airway and cervical Spine.

B. Breathing and ventilation.

C. Circulation and bleeding control.

D. Disability and neurologic assessment.

E. Exposure and environment control.

To complete the primary survey, all polytrauma unstable patients were exposed in the resuscitation room to the following: (1) FAST (Focused assessment sonography for trauma patient): in for possible internal hemorrhage. (2) Portable chest and pelvis X-ray: Anteroposterior supine view for unstable patients using shimadzu collimator $r$-20c portable $x$ ray device.

\section{The secondary survey:}

I. After initial resuscitation effort, all patients were subjected to full history taking.

II. AMPLE History taking:

A $=$ Allergies

$\mathbf{M}=$ Medication currently used.

$\mathbf{P}=$ Past illnesses $/$ Pregnancy .

$\mathbf{L}=$ Last meal.

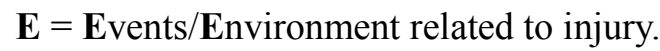

III. Clinical examination of the patients at the Trauma Room including

1) Vital signs:

2) Local examination:

3) Neurological examination: Glasgow Coma Scale (GCS) and examine for lateralization signs.

4) Complete general examination: head-to-toe examination to define other associated or occult injuries.

IV. Investigations: Laboratory tests and radiological investigations:

\section{Interventions}

$\circ$ The patients fulfilling the inclusion criteria were divided randomly and equally into tranexamic and control groups.

- Tranexamic group: patients received a loading dose of $1 \mathrm{~g}$ tranexamic acid infused over 10 minutes, followed by an intravenous infusion of $1 \mathrm{~g}$ over eight hours.

○ Control group received $0.9 \%$ normal saline in the same order.

- Other treatments protocols and care were routinely done for all patients. Data were recorded in the checklist by interview and patients' charts.

- Two CT brain scans for each participant were obtained, the first before randomization and the second 24-48 hours later.

\section{Ethical considerations:}

An approval of the study was obtained from Mansoura University Academic and Ethical Committee. Informed written consent was obtained from the relatives of the patients sharing in the study. Confidentiality and personal privacy was respected in all levels of the study.

\section{Statistical analysis}

Data were fed to the computer and analyzed using IBM SPSS software package version 20.0. Qualitative data were expressed as number and percentage. Quantitative data were expressed as mean, standard deviation, and median (minimum and maximum). Data were tested for normality using Kolmogorov-Smirnov test. All tests were 2 tailed. The unpaired t-test was used to compare the means of the two groups. Chi-square $\left(\chi^{2}\right)$ test or Fisher's exact test (FET) was used for comparison between groups as regards qualitative data. A significant $p$-value was considered when it is equal or less than 0.05 .

\section{RESULTS}

Most of the studied cases were males of middle age. There were no significant statistical differences between different modes of trauma in both groups (Table 1). 
Table (1): Demographic data and modes of trauma of the studied cases

\begin{tabular}{|c|c|c|c|}
\hline & $\begin{array}{c}\text { Tranexamic group } \\
(\mathrm{N}=50)\end{array}$ & $\begin{array}{c}\text { Control group } \\
(\mathrm{N}=50)\end{array}$ & $P$ value \\
\hline \multicolumn{4}{|l|}{ Age: } \\
\hline Mean \pm SD & $29.5 \pm 10.9$ & $29.1 \pm 10.3$ & \\
\hline \multicolumn{4}{|l|}{ Gender: } \\
\hline Male & $41(82 \%)$ & $39(78 \%)$ & \multirow{2}{*}{0.803} \\
\hline Female & $9(18 \%)$ & $11(22 \%)$ & \\
\hline \multicolumn{4}{|c|}{ Mode of trauma: } \\
\hline MVC & $19(38 \%)$ & $17(34 \%)$ & 0.835 \\
\hline RTA & $13(26 \%)$ & $15(30 \%)$ & 0.823 \\
\hline FFH & $9(18 \%)$ & $7(14 \%)$ & 0.785 \\
\hline Struggle & $9(18 \%)$ & $11(22 \%)$ & 0.803 \\
\hline
\end{tabular}

There was no significant difference between the 2 groups as regard GCS and grading of TBI (Table 2).

Table (2): Clinical assessment of the studied cases according to GCS

\begin{tabular}{|l|c|c|c|}
\hline & $\begin{array}{c}\text { Tranexamic group } \\
(\mathbf{N}=50)\end{array}$ & $\begin{array}{c}\text { Control group } \\
(\mathbf{N}=50)\end{array}$ & \multirow{2}{*}{ P value } \\
\hline GCS: & $9(3-15)$ & $10(3-15)$ & \multirow{2}{*}{0.8645} \\
\hline Median (Min- Max) & $8.11 \pm 3.03$ & $8.21 \pm 2.81$ & \multirow{2}{*}{0.087} \\
\hline Mean \pm SD & $13(26 \%)$ & $17(34 \%)$ & \multirow{2}{*}{} \\
\hline Grading of TBI: & $27(54 \%)$ & $24(48 \%)$ & \\
\hline Mild (13-15) & $10(20 \%)$ & $9(18 \%)$ & \\
\hline Moderate (9-12) & &
\end{tabular}

There were no significant differences in the $1^{\text {st }} \mathrm{CT}$ brain findings (Table 3 ).

Table (3): Analysis of the $1^{\text {st }} \mathrm{CT}$ brain findings in the studied groups

\begin{tabular}{|c|c|c|c|}
\hline CT findings $^{\#}$ & $\begin{array}{c}\text { Tranexamic group } \\
(\mathbf{N = 5 0 )}\end{array}$ & $\begin{array}{c}\text { Control group } \\
(\mathbf{N}=\mathbf{5 0})\end{array}$ & P value \\
\hline EDH & $16(32 \%)$ & $19(38 \%)$ & 0.675 \\
\hline SDH & $11(22 \%)$ & $13(26 \%)$ & 0.814 \\
\hline ICH & $10(20 \%)$ & $12(24 \%)$ & 0.809 \\
\hline Total volume & $20.9 \pm 5.31$ & $21.4 \pm 5.9$ & 0.1188 \\
\hline SAH & $13(26 \%)$ & $9(18 \%)$ & 0.468 \\
\hline SAH scale & $1.11 \pm 0.38$ & $1.17 \pm 0.25$ & 0.683 \\
\hline IVH & $12(24 \%)$ & $9(18 \%)$ & 0.623 \\
\hline Brain edema & $9(18 \%)$ & $11(22 \%)$ & 0.802 \\
\hline Mass effect & $9(18 \%)$ & $7(14 \%)$ & 0.785 \\
\hline
\end{tabular}

${ }^{\#}$ CT findings are not mutually exclusive, so totals can be $>100 \%$

The follow up CT brain showed that the volume expansion, the hemorrhagic masses, PIH, and SAH scale were significantly different between both groups (Table 4 ). 
Table (4): Effect of Tranexamic acid on $2^{\text {nd }} \mathrm{CT}$ brain findings

\begin{tabular}{|c|c|c|c|}
\hline & $\begin{array}{c}\text { Tranexamic group } \\
(\mathrm{N}=50)\end{array}$ & $\begin{array}{c}\text { Control group } \\
(\mathrm{N}=50)\end{array}$ & $P$ value \\
\hline \multicolumn{4}{|c|}{ Hemorrhagic mass volume and growth $(\mathrm{ml})$ : } \\
\hline Total volume & $22.7 \pm 6.1$ & $26.3 \pm 5.8$ & \multirow{2}{*}{$0.0384^{*}$} \\
\hline Expansion & $1.5 \pm 4.4$ & $5.1 \pm 11.3$ & \\
\hline \multicolumn{4}{|c|}{ Change of hemorrhagic mass volume: } \\
\hline Reduced & $34(68 \%)$ & $21(42 \%)$ & $0.016^{*}$ \\
\hline \multicolumn{4}{|c|}{ Progressive Intracranial Hemorrhage (PIH): } \\
\hline $\mathrm{N}(\%)$ & $1 / 5(20 \%)$ & $4 / 11(36.4 \%)$ & 0.513 \\
\hline \multicolumn{4}{|l|}{ SAH scale: } \\
\hline Mean \pm SD & $1.07 \pm 0.29$ & $1.35 \pm 0.33$ & $0.0481 *$ \\
\hline \multicolumn{4}{|l|}{ Mass effect: } \\
\hline $\mathrm{N}(\%)$ & $10(20 \%)$ & $12(24 \%)$ & 0.8092 \\
\hline \multicolumn{4}{|c|}{ New hemorrhagic lesion: } \\
\hline $\mathrm{N}(\%)$ & $3(6 \%)$ & $5(10 \%)$ & 0.7124 \\
\hline \multicolumn{4}{|c|}{ New focal ischemic regions: } \\
\hline $\mathrm{N}(\%)$ & $2(4 \%)$ & $6(12 \%)$ & 0.269 \\
\hline
\end{tabular}

*: Significant

Tranexamic group was associated with significantly improved motor GCS than control group, with less neurosurgical intervention in tranexamic group (Table 5).

Table (5): Clinical Outcome of the studied cases

\begin{tabular}{|c|c|c|c|}
\hline & $\begin{array}{c}\text { Tranexamic group } \\
(\mathbf{N = 5 0})\end{array}$ & $\begin{array}{c}\text { Control group } \\
(\mathbf{N = 5 0})\end{array}$ & P value \\
\hline Improved motor GCS after 24 hours: \\
\hline $\mathrm{N}(\%)$ & $35(70 \%)$ & $25(50 \%)$ & 0.066 \\
\hline \multicolumn{3}{|l|}{ Neurosurgical intervention after 2 ${ }^{\text {nd }}$ CT brain: } \\
\hline $\mathrm{N}(\%)$ & $8(16 \%)$ & $14(28 \%)$ & 0.227 \\
\hline
\end{tabular}

The secondary outcome of the studied cases were assessed regarding hospital LOS which was $<28$ days $58 \%$ (29 patients) in tranexamic group 36\% (18 patients) in control group and unfavorable GOS in $31.1 \%$ of tranexamic group and $41.4 \%$ of control group with significant statistical difference toward tranexamic group (Table 6).

Table (6): Comparison of the outcome of the studied groups

\begin{tabular}{|c|c|c|c|}
\hline & $\begin{array}{c}\text { Tranexamic group } \\
(\mathbf{N = 5 0})\end{array}$ & $\begin{array}{c}\text { Control group } \\
(\mathbf{N}=50)\end{array}$ & \multirow{2}{*}{ P value } \\
\hline Hospital Length Of Stay (LOS): & \multirow{2}{*}{$0.0451^{*}$} \\
\hline$<28$ days & $29(58 \%)$ & $18(36 \%)$ & \\
\hline$>28$ days & $21(42 \%)$ & $32(64 \%)$ & \multirow{2}{*}{0.3873} \\
\hline Mortality rate: & $5(10 \%)$ & $9(18 \%)$ & \multirow{2}{*}{0.067} \\
\hline Died & $45(90 \%)$ & $41(82 \%)$ & \\
\hline Survived & $14(28.1 \%)$ & $17(34 \%)$ & \\
\hline \multicolumn{2}{|c|}{ Unfavorable Outcome (GOS) at discharge: } \\
\hline
\end{tabular}

*: Significant 


\section{DISCUSSION}

In the present study, most of the studied cases were middle aged males. Yutthakasemsunt and others ${ }^{(7)}$ also reported that $86 \%$ of tranexamic group and $91 \%$ of placebo group were males of middle age. Similarly Junaid and his colleagues ${ }^{(8)}$ stated that the majority of patients $47.2 \%$ belonged to $21-40$ years age group, with average age of $27 \pm 16$ years. Jokar and his colleagues (9) too informed that male presentation prevailed in $80 \%$ and $70 \%$ with the mean age values were $35.4 \pm 14.6$ and $36.2 \pm 14.9$ years in tranexamic acid group and placebo group with close relationship in between. Also, Fakharian et al. ${ }^{(10)}$ found that $90.5 \%$ of tranexamic group and $88 \%$ of placebo group were males with age mean of $42.3 \pm 18.3$ and $39.3 \pm 18.1$ years respectively.

In this study, the most common mode of trauma in both groups was MVC, followed by RTA, struggle, and without significant statistical differences in both groups. In the same way, Junaid and his colleagues ${ }^{(8)}$ informed that their results reflected that RTA is a major source of hospital admissions and disability and devastating economic problems. Moreover, Fakharian et al. ${ }^{(10)}$ clarified that RTA was the most common mode of trauma in $86.5 \%$ of tranexamic group and $82.7 \%$ of placebo group followed by $\mathrm{FFH}$ in $10.8 \%$ and $10.7 \%$, struggle in $2.7 \%$ in both groups respectively with no statistical differences $(\mathrm{P}=0.43)$.

In the present study, the mean values of GCS were closely approximated in tranexamic group and control group. TBI were classified into 3 grades according to GCS and clinical manifestations: mild, moderate, and severe without significant statistical difference between the 2 groups. Correspondingly, Perel et al. ${ }^{(3)}$ stated that tranexamic group and placebo group were classified into 3 grades: mild in 47\% (63 patients) vs. $42 \%$ (58 patients); moderate in $19 \%$ (25 patients) vs. 25\% (34 patients); and severe 34\% (45 patients) vs. $33 \%$ (45 patients) respectively in both groups without significant statistical difference. Also, Yutthakasemsunt and others ${ }^{(7)}$ excluded mild TBI and divided TBI into moderate (9-12): 43.3\% (52 patients) of tranexamic group, $39.8 \%$ (47 patients) of placebo group; and severe (4-8) 56.7\% (68 patients) of tranexamic group, $60.2 \%$ (71 patients) of placebo group without significant difference between the 2 groups. Fakharian et al. ${ }^{(10)}$ also reported that the GCS mean values were closely approximated $(\mathrm{P}=0.14)$ in tranexamic acid group $(12.7 \pm 2.83)$ and placebo group $(11.65 \pm 3.71)$.

In this study, the most common $1^{\text {st }} \mathrm{CT}$ brain finding in both groups was $\mathrm{EDH}$ followed by $\mathrm{SDH}$, $\mathrm{ICH}, \mathrm{SAH}, \mathrm{IVH}$, brain edema and mass effect without significant differences between both groups. Also, Perel et al. ${ }^{(3)}$ stated that the $1^{\text {st }} \mathrm{CT}$ brain findings were closely distributed without significant statistical differences in tranexamic and placebo groups respectively as follows: hemorrhagic contusion in $48 \%$
(61 patients) vs. 51\% (66 patients); SDH in 30\% (38 patients) vs. $35 \%$ (45 patients); $\mathrm{EDH}$ in $30 \%$ (38 patients) vs. $22 \%$ (28 patients); $\mathrm{ICH}$ in $7 \%$ (9 patients) vs. $12 \%$ (15 patients); SAH in $43 \%$ (55 patients) vs. $61 \%$ (79 patients) and mass effects including sulcal effacement in $46 \%$ vs. $57 \%$, ventricular effacement in $29 \%$ vs. $33 \%$, and compressed cisterns in $9 \%$ vs. $10 \%$. Likewise, Yutthakasemsunt and others ${ }^{(7)}$ informed that mass effects on the $1^{\text {st }} \mathrm{CT}$ scan were closely approximated in tranexamic group and placebo group: midline shift (>3 mm) in $1.7 \%$ ( 2 patients) vs. $2.5 \%$ (3 patients) and basal cistern compression in $45 \%$ (45 patients) vs. $44.2 \%$ (53 patients) respectively. Equally, Jokar and his colleagues ${ }^{(9)}$ stated that there was no significant differences in the primary CT brain findings between tranexamic group and placebo group: EDH (7.5\% vs. $7.5 \%)$; $\mathrm{SDH}(7.5 \%$ vs. $10 \%)$; and $\mathrm{ICH}(35 \%$ vs. $32.5 \%)$ with initial volume $(21.6 \pm 5.37$ vs.

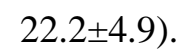

In the present study, the $2^{\text {nd }} \mathrm{CT}$ brain showed that there were significant differences between both groups as regard hemorrhage growth, the hemorrhagic masses, PIH, and SAH scale. There were mass effects, new hemorrhagic lesions, and new focal ischemic lesions in both groups without significant differences. Also, Jokar and his colleagues (9) reported that tranexamic acid reduced significantly $(\mathrm{P}<0.001)$ the hemorrhagic mass growth as the expansion mean values were $1.7 \pm 9.7 \mathrm{ml}$ in tranexamic group vs. $4.3 \pm 12.9 \mathrm{ml}$ in control group. In the same way, Fakharian et al. (10) published that tranexamic acid had a significant effect $(\mathrm{P}=0.03)$ on the hemorrhagic mass volume as volume was reduced in $68.5 \%$ vs. $50.7 \%$, increased in $20.5 \%$ vs. $22.7 \%$, and stationary in $11 \%$ vs. $26.7 \%$ in tranexamic group and placebo group respectively. Also, new hemorrhage occurred closely in both groups $(23.33 \%$ vs. $18.7 \% ; \mathrm{P}=0.21)$. Harmoniously, Perel et al. (3) clarified that in the tranexamic acid and placebo groups respectively, the mean total hemorrhage growth was $(5.9 \pm 26.8 \mathrm{ml})$ and $(8.1 \pm 29.2 \mathrm{ml}), \mathrm{PIH}$ occurred in $36 \%$ (44 patients) and 44\% (56 patients) patients, change in the SAH scale was -0.11 for tranexamic acid and -0.12 for control patients, new hemorrhage areas occurred in 11\% (13 patients) and 16\% (20 patients), signs of mass effect occurred in $47 \%$ (58 patients) and $60 \%$ (76 patients), and new focal cerebral ischemic lesions occurred in 5\% (6 patients) and 9\% (12 patients). However, the adjusted analysis showed no significant differences between both groups. In consistent with these findings, Yutthakasemsunt and others ${ }^{(7)}$ reported that $\mathrm{PIH}$ was lower in tranexamic group than placebo group $18 \%$ (21 patients) and $27 \%$ (32 patients) but without significant difference between the 2 groups $(\mathrm{P}=0.1036)$. Also, increased mass effects were found in $10 \%$ (11 patients) of tranexamic group and $11 \%$ (12 patients) of control group without statistical difference $(\mathrm{P}=0.9824)$. 
In this study, the clinical outcome was better in tranexamic group as it was associated significantly with improved motor GCS and less neurosurgical intervention. Also, Fakharian et al. ${ }^{(10)}$ reported that $10.8 \%$ of tranexamic group vs. $16 \%$ of control group underwent neurosurgical intervention but without significant difference. In contrast, Perel et al. (3) informed that $15 \%$ (20 patients) in tranexamic acid group and $15 \%$ (21 patients) in placebo group had neurosurgery other than those evacuations based on first brain scan findings (adjusted odds ratio 0.98 (0.45 to 1.93) $\mathrm{P}=0.95$ ). But, Yutthakasemsunt et al. ${ }^{(7)}$ stated that improved motor GCS was equally distributed in both groups $31 \%$ (37 patients) for each group, while neurosurgical interventions were performed only in $3 \%$ of tranexamic acid group.

The significant statistical differences in hemorrhage growth and clinical outcome between the current study and other studies can be explained by the early administration of tranexamic acid (within 3 hours of injury onset) to decrease the extent of the bleeding before the hemorrhagic volume may become dangerous. On the contrary, late administration can be useless, once a significant hemorrhage has accumulated, or even dangerous ${ }^{(\mathbf{1 1})}$.

In the current study, the secondary outcome of the studied cases was better in tranexamic acid group, which was associated with less hospital LOS, and better GOS. Also, Perel et al. ${ }^{(3)}$ stated that there were $11 \%$ (14 patients) deaths in tranexamic acid group and 18\% (24 patients) in placebo group and 22\% (26 patients) in the tranexamic acid group and $26 \%$ (29 patients) in the placebo group of survivors were discharged $\geq 28$ days with no significant difference. But, $45 \%$ (60 patients) patients in the tranexamic acid group and 58\% (80 patients) in the placebo group had poor GOS with significant difference $(\mathrm{P}=0.04)$. Yutthakasemsunt $\boldsymbol{e t}$ al. (7) also clarified that the secondary outcome was better in tranexamic group: less mortality rate [10\% (12 patients) vs. $14 \%$ (17 patients)]; and less unfavorable GOS [18\% (21 patients) vs. $23 \%$ (27 patients)], but the difference was not significant. Moreover, Fakharian $\boldsymbol{e t}$ al. (10) informed that the tranexamic group was associated with lower mortality rate $(2.7 \%$ vs. $4 \%)$ and less unfavorable GOS at discharge (10.8\% vs. $17.3 \%)$ in both groups respectively, but with no significant differences between both groups.

\section{CONCLUSION}

TBI that is associated with intracranial hemorrhage has high risk of coagulopathy, which may worsen hemorrhagic mass volume.

- The management of TBI should emphasize on prevention of secondary brain insults as hypoxia, hypoperfusion and hematoma expansion.
- Early administration of tranexamic acid (within 3 hours of injury onset) can limit the extent of bleeding before the hemorrhagic volume may become dangerous, while late administration can be useless.

- Early administration of tranexamic acid is associated with less hospital resources usage, lower mortality rate and better functional outcome.

\section{REFERENCES}

1. Menon D, Schwab K, Wright D et al. (2010): Position statement: definition of traumatic brain injury. Archives of Physical Medicine and Rehabilitation, 91(11): 16371640 .

2. Joris P, Mensink R, Adam T et al. (2018): Cerebral blood flow measurements in adults: A review on the effects of dietary factors and exercise. Nutrients, 10(5): 530-35.

3. Maas A, Stocchetti N, Bullock R (2008): Moderate and severe traumatic brain injury in adults. The Lancet Neurology, 7(8): 728-741.

4. Perel P, Salman R, Kawahara $T$ et al. (2012): CRASH-2 (Clinical Randomisation of an Antifibrinolytic in Significant Haemorrhage) intracranial bleeding study: the effect of tranexamic acid in traumatic brain injury-a nested, randomised, placebo-controlled trial. Health technology assessment (Winchester, England), 16(13): 1-6.

5. Gleeson N, Buggy F, Sheppard B et al. (1994): The effect of tranexamic acid on measured menstrual loss and endometrial fibrinolytic enzymes in dysfunctional uterine bleeding. Acta Obstet Gynecol Scand., 73: 274277.

6. Roberts I, Perel P, Prieto-Merino D et al. (2012): Effect of tranexamic acid on mortality in patients with traumatic bleeding: prespecified analysis of data from randomized controlled trial. BMJ Br Med J., 345: 583945.

7. Yutthakasemsunt S, Kittiwatanagul W, Piyavechvirat $P$ et al. (2013): Tranexamic acid for patients with traumatic brain injury: a randomized, double-blinded, placebo-controlled trial. BMC Emergency Medicine, 13(1): 20-26.

8. Junaid M, Afsheen A, Tahir A et al. (2016): Changing spectrum of traumatic head injuries: Demographics and outcome analysis in a tertiary care referral center. J Pak Med Assoc., 66(7): 864-868.

9. Jokar A, Ahmadi K, Salehi T et al. (2017): The effect of tranexamic acid in traumatic brain injury: a randomized controlled trial. Chinese Journal of Traumatology, 20(1): 49-51.

10. Fakharian E, Abedzadeh-Kalahroudi M, Atoof $F$ (2018): Effect of tranexamic acid on prevention of hemorrhagic mass growth in patients with traumatic brain injury. World Neurosurgery, 109: 748-753.

11. Taccone F, Citerio G, Stocchetti N (2019): Is tranexamic acid going to CRASH the management of traumatic brain injury? Intensive Care Med., 46: 12611263. 